\title{
DOS PRINCIPADOS HEREDITÁRIOS: OS JOVENS EXECUTIVOS E AS DEMANDAS DA CARREIRA
}

\author{
ABOUT HEREDITARIAN PRINCIPALITIES: \\ YOUNG EXECUTIVES AND CAREER DEMANDS
}

Data de submissão: $21 / 07 / 2013$ Aceite: 05/04/2014

\author{
José Antônio Gontijo do Couto ${ }^{1}$ \\ Antonio Carvalho Neto ${ }^{2}$ \\ Ana Lúcia Sant'Ana ${ }^{3}$ \\ Pedro Paulo Barros Gonçalves ${ }^{4}$ \\ Fernanda Versiani ${ }^{5}$
}

\section{RESUMO}

Este estudo tem como objetivo analisar se o jovem executivo herdeiro equilibra a vida profissional e a vida pessoal. Foram ouvidos 15 jovens executivos mineiros, herdeiros das empresas de médio e grande porte. A pesquisa identificou fontes de satisfação e de insatisfação relacionadas ao sentido e ao processo do trabalho desses jovens. Foram analisados sentimentos relativos às possibilidades de crescimento profissional, inter-relacionando as obrigações de trabalho (vida profissional) e as atividades e tempo dedicados ao não-trabalho (vida pessoal). Também foi analisado o conteúdo do papel executivo, buscando diagnosticar as dimensões básicas das tarefas executadas em relação à autonomia, identidade da tarefa e significação do trabalho. Os resultados indicaram que os jovens executivos herdeiros estão satisfeitos com o nível de distribuição do tempo e da energia dedicados ao trabalho e ao não-trabalho. Por outro lado, estes jovens estão submetidos a um sistema de dominação racionalmente legitimado pela expectativa dos pais, elemento fundamental no processo da continuidade e da sobrevivência da empresa, por ocuparem um espaço específico já delimitado: são executivos "filhos do dono". Prisioneiros da obra do predecessor e condenados a vencer por meio da continuidade de sua obra, os jovens executivos herdeiros carregam o peso da herança no cumprimento do papel esperado desde muito jovens pelo pai, família e círculo social.

Palavras - Chave: Jovens executivos; Herdeiros; Carreira; Vida profissional; Vida pessoal.

\footnotetext{
${ }^{1}$ Possui graduação em Administração pela Pontifícia Universidade Católica de Minas Gerais - PUC, Minas e mestrado profissional em andamento em Administração pela Pontifícia Universidade Católica de Minas Gerais - PUC Minas. Belo Horizonte. Minas Gerais. Brasil. E-mail: jcouto@ fiemg.com.br

2 Possui graduação em Arquitetura e Urbanismo pela Universidade Federal do Rio de Janeiro - UFRJ. Atualmente é Professor Adjunto IV da Universidade Federal do Ceará, Professor da University of Oxford e Diretor Executivo do Associação Nordeste Brasileira Construção Metálicas. Fortaleza. Ceará. Brasil. E-mail: carvalhoneto@pucminas.br

${ }^{3}$ Possui graduação em Relaçãoes Internacionais pela Pontifícia Universidade Católica de Minas Gerais - PUC Minas. Belo Horizonte, Minas Gerais. Brasil.E-mail: analucia_vcs@hotmail.com

${ }^{4}$ Possui graduação em Relações Internacionais pela Pontifícia Universidade Católica de Minas Gerais - PUC Minas e mestrado em Planejamento Urbano e Regional pela Universidade Federal do Rio de Janeiro - UFRJ. Rio de Janeiro. Rio de Janeiro. Brasil. E-mail: pedropbg@yahoo.com.br ${ }^{5}$ Possui graduação em Publicidade e Propaganda pelo Centro Universitário Newton Paiva - CNP e Mestrado Acadêmico em Administração na Universidade PUC Minas (PPGA). Belo Horizonte. Minas Gerais. Brasil. E-mail: nandaversiani@gmail.com
} 


\begin{abstract}
This study aims to discuss the balance between professional and personal life of young heir executives. We interviewed fifteen young executives from Minas Gerais, Brazil, heirs of medium and big firms. The research showed sources of (in) satisfaction related to the meaning and the work process of these young executives. We discussed how they feel towards the possibilities of career advancing relating the professional obligations and the activities dedicated to personal life and leisure. It was discussed also the contents of the role of the executive to diagnosticate the basic dimensions of the tasks executed related to autonomy, identity of the task and significance of work. The results indicate that the young heir executives are satisfied with the distribution of both time and energy dedicated to work and non-working time. These executives are under a domination system rationally legitimated by parent expectations, a fundamental element in the process of continuity and survival of the firm because they occupy a specific space previously delimitated: they are the "owner children". Prisoners of their predecessor life work and condemned to win through the continuity of their fathers' work, the young heir executives take the burden of the heritage to fulfill the role expected since very young.
\end{abstract}

Keywords: Young executives; Heirs; Career; Professional life; Personal life.

\title{
1 INTRODUÇÃO
}

É muito raro encontrar estudos sobre a percepção de jovens executivos que sejam herdeiros sobre sua vida profissional, como o que se propõe fazer neste artigo. A literatura trata em sua grande maioria de executivos de carreira, que não são herdeiros das empresas em que trabaIham. Muitos autores tratam de empresas familiares, de sucessão e outras temáticas correlatas, mas não desta temática específica (FREITAS; BARTH, 2012; BELMONTE; FREITAS, 2013).

Sucesso na carreira e equilíbrio entre a vida profissional e pessoal são dualidades vivenciadas pelos executivos de carreira. Imersos nas diversas demandas da contemporaneidade, protagonistas na dinâmica organizacional, mediam processos sociais, tecnológicos, culturais, políticos e ideológicos (DAVEL; MELO, 2005). Vivenciam conflitos e contradições (MINTZBERG, 1986). O trabalho destes executivos se constitui na complexidade, na sobrecarga e em meio à tensão marcada por um contingente de profissionais disputando um invejado espaço de poder (SERVA; FERREIRA, 2004). Para atender às expectativas do ideal de sucesso, objetivos econômicos são deslocados para o plano psicológico, tornando os executivos condenados a vencer (PAGÈS et al., 2006).

Os executivos de carreira dispendem um excesso de tempo e energia na construção do sucesso profissional, comprometendo investimentos em outras dimensões necessárias da vida, como as relações afetivas, familiares e o lazer. (TANURE; CARVALHO NETO; ANDRADE, 2007). Os executivos de hoje se veem ainda mais obrigados a refletirem e repensarem sobre a vida profissional em consonância com a vida pessoal (DAVEL; MELO, 2005). Diante desses questionamentos, o presente trabalho teve por objetivo analisar a percepção de jovens executivos herdeiros sob o discurso de satisfação entre o equilíbrio da vida profissional e pessoal.

Por que herdeiros? São jovens executivos em situação específica, muitas vezes exercendo uma autoridade pela linhagem. No Brasil, há um número significativo de empresas familiares que são geridas pelos sucessores (FREITAS; BARTH, 2012; BELMONTE; FREITAS, 2013). Daí, então, a importância de pesquisar como o jovem executivo herdeiro equilibra as demandas da vida profissional e pessoal, vis-à-vis o jovem executivo de carreira.

A dedicação quase exclusivamente voltada para a empresa parece ser a regra de sobrevivência nas organizações modernas e o único caminho de sucesso na carreira executiva (EVANS; BARTOLOMÉ, 1980; SERVA; FERREIRA, 2004). A maioria dos executivos de carreira paga um elevado custo para manter o foco em sua carreira, no que se refere à saúde física e ao bem-estar 
emocional, vivenciando contradições, oportunidades e medos, tentando buscar um significado coerente entre sucesso profissional e felicidade.

O presente estudo contribui para a discussão deste fenômeno em relação a um grupo pouco pesquisado nesta dimensão, jovens executivos herdeiros, tendo como foco amostral da pesquisa um grupo destes jovens organizado pela Federação das Indústrias do Estado de Minas Gerais - FIEMG, através do programa denominado FIEMG Jovem.

Para facilitar a leitura e a compreensão, toda vez que se referir neste artigo a "executivos de carreira", está-se referindo a executivos que não são herdeiros, a executivos que trabalham para empresas das quais não são donos. Toda vez que se referir a "jovens executivos herdeiros", está-se referindo ao objeto deste estudo.

\section{REFERENCIAL TEÓRICO}

Há pelo menos trinta anos o mundo dos negócios passa por uma reestruturação produtiva que reúne elementos de racionalização técnica e organizacional (RUIZ, 2003; ENRIQUEZ, 2006), buscando enfrentar o aumento da competitividade num cenário econômico liberal (ANTUNES, 1995; CHANLAT, 2000; TANURE; CARVALHO NETO; ANDRADE, 2007).

Esse contexto desafia sobremaneira os executivos, diante de desafios como: contínuos problemas de mercado; transformações geradas por fusões e aquisições; maior internacionalização da economia. Não é mais tão rara nem mesmo a mudança do presidente. É como se cada um tivesse que se reinventar a toda hora, como se isso fosse possível. É um sentimento de delírio permanente (CHANLAT, 1995; SENNETT, 2000; KILIMNIK; SANT'ANNA; CASTILHO, 2004).

Refém das exigências organizacionais e do excesso de tempo que dedica ao trabalho, o executivo não raramente sente prazer em estar permanentemente ocupado e até mesmo seduzido pela fantasia da "insubstitutibilidade", não se colocando limite nos usos dos tempos e dos compromissos que possam harmonizar melhor seu investimento na vida pessoal e na vida profissional (EVANS, 1996; TREMBLAY, 2002, 2004). É nuclear a neurose de excelência, a necessidade de trabalhar buscando bater metas cada vez mais audaciosas (AUBERT, 2007).

Outro fator que sequestra o tempo do executivo é o uso das novas tecnologias (PERISTA; MAXIMIANO; FREITAS, 2000). Neste aspecto, os executivos jovens, que interagem intensamente com a tecnologia e a dominam muito mais do que a geração imediatamente anterior (Perrone, Engelman, Santos e Sobrosa, 2013), estão muito mais propícios a este sequestro do seu tempo. Em um extremo, estão os escravos das novas tecnologias e, no outro, os usuários facilitadores. Pesquisas indicam que a proporção de "escravizados" é muito superior. No pretenso tempo de não-trabalho, o executivo mantém-se "conectado" o tempo todo nas demandas do trabalho. Neste estudo, os autores identificaram um predomínio do tempo de trabalho em detrimento do tempo de não-trabalho, o que caracteriza o fenômeno denominado workaholic, da compulsão pelo trabalho (TANURE; CARVALHO NETO; ANDRADE, 2007).

\subsection{0 culto ao workaholic e as tensões no papel executivo}

São elementos considerados como básicos na identificação de indivíduos com o padrão de comportamento workaholic: gastar grande parte de seu tempo no trabalho; persistir em pensar frequentemente no trabalho, mesmo quando não estão efetivamente trabalhando; trabalhar muito além do que é razoavelmente esperado do cargo que ocupam; não conseguir controlar ou reduzir o excesso de trabalho; necessidade de controlar o ambiente por serem perfeccionistas; e 
responder positivamente à competição. (SERVA e FERREIRA, 2004)

O estudo de Tanure, Carvalho Neto e Andrade (2007) evidenciou fontes de tensão que estão intimamente relacionadas com o culto ao workaholism: a sensação percebida pelo executivo de que o tempo é um recurso extremamente escasso para viver e aproveitar as outras dimensões de sua vida fora do trabalho; os traumas com as mudanças organizacionais, cada vez mais profundas e constantes nas empresas; a sensação de dívida permanente, referindo-se à sensação do executivo de que nunca dá conta das demandas cada vez maiores e mais complexas por parte das empresas (HUY; MINTZBERG, 2003); o orgulho pelo que faz, derivado da sensação de "pertencimento" a uma empresa, de identificação de seus valores pessoais com os valores da organização; e o teatro corporativo, o jogo de cena comum dentro do ambiente de trabalho.

O executivo é um prisioneiro do seu papel, vivenciando um fascínio pelo cargo, pelo status, pelo poder e pelo dinheiro trazido para sua vida. O executivo se realiza na carreira, mas o seu dilema é gerenciar o limite entre trabalho, lazer, vida afetiva e família (CASTELLS, 1999; CHANLAT, 2000; DE VRIES, 2004).

Serva e Ferreira (2004), Tanure, Carvalho Neto e Andrade (2007) ressaltam a deificação do executivo como uma expressão desse fenômeno, representado pelo sentimento e fascínio projetado como exemplo de lucidez e perspicácia e de uma inabalável perseguição de objetivos: seria o "super-homem" com todos os seus poderes. Condenado a vencer, sua carreira é uma canalização de energia, um elemento central que media sua relação com o tempo (PAGÈS et al. 2006).

A realização, o reconhecimento e os desafios têm maior peso na vida do alto executivo, até mais que a remuneração. Entretanto, sobre este profissional recaem enormes expectativas não só de seus pares e subordinados, mas de seus amigos e familiares. Isto pesa muito, num quadro de deificação que, não raramente, torna por si só fonte de estresse e de solidão, pois esse super-homem não pode demonstrar fraqueza ou dúvidas (SCANFONE; CARVALHO NETO; TANURE, 2007).

Para Dejours (1996), o sujeito no trabalho está permanentemente negociando a melhor forma de trabalhar. $O$ risco é quando o executivo sente que o trabalho é a única parte divertida da vida, sendo sua vida pessoal, afetiva e familiar uma obrigação (LAPIERRE, 1995; TANURE; CARVALHO NETO; ANDRADE, 2007).

\subsection{Jovens executivos de carreira no cenário das organizações}

A exigência social sofrida pelo jovem executivo de carreira, que não é herdeiro, em relação ao seu pretendido sucesso, torna-o muitas vezes inseguro, em uma idade onde a necessidade de aprovação social é grande. $O$ indivíduo é tomado por uma tentativa perpétua de superar-se. "Para satisfazer a esta ambição, ele aceita a escravidão" (PAGÈS, 2006, p. 141). É a luta pelo reconhecimento social que passa ao centro da vida (ENRIQUEZ, 1990).

Mais do que os aspectos técnicos relacionados ao trabalho, os jovens executivos de carreira interiorizam as formas de comportamento desejadas pela empresa, para obter aprovação, de forma que os valores da empresa superam a esfera do campo do trabalho, atingindo outras dimensões da vida deles (TOLEDO, 2006). A geração mais jovem é regida por uma diferente ética em relação ao trabalho, a ética do prazer, enquanto as gerações mais velhas têm a ética do dever como base de suas ações (OSTROFF; ATWATER, 2003).

Estudos apontam uma manifestação especial de otimismo pelo jovem executivo de carreira, constituído na convicção de que o mundo e a vida fazem sentido, em parte devido à natureza otimista da própria da idade (MORIN, 2001; PIMENTA; THIRY-CHERQUES, 2006). O sentimento que parece predominar estes jovens é que, uma vez que o mundo deve fazer algum sentido, as 
questões éticas e morais se resolverão mediante o cumprir das regras vigentes no meio organizacional (PIMENTA; THIRY-CHERQUES, 2006).

Ao fazer parte da organização, o importante é a satisfação pessoal e o próprio projeto de vida, dentro e fora da organização. Entretanto, com uma hierarquia organizacional enxuta, há poucas vagas. E elas já estariam, então, destinadas àqueles que têm um projeto de vida de serem os melhores dentre os melhores (SCHIRATO, 2006).

Apesar de se queixarem muito da alta carga de trabalho, com o número excessivo de horas dedicado à organização e de perceberem mais do que os seniores os prejuízos causados à sua vida pessoal (TANURE; CARVALHO NETO; ANDRADE, 2007), os jovens executivos de carreira se encontram em um ciclo ideológico de obediência e submissão que impede a expressão de seus desejos individuais (BULGACOV; TOLEDO, 2004). A repressão constante de seus desejos deságua em um elenco de doenças físicas devidas a questões emocionais mal resolvidas (DEJOURS, 1996).

Os jovens executivos de carreira que não se adaptam ou buscam equilibrar melhor a vida pessoal e profissional geralmente são excluídos das empresas (TOLEDO, 2006). É um mundo onde os "fracos" não têm vez (CARVALHO NETO et al., 2009).

Para Ostroff e Atwater (2003), o jovem executivo de carreira pertence a uma geração que possui valores diferentes com relação aos da geração dos executivos maduros. Considerando mais o prazer como sentimento incluído na escolha profissional, ele é levado a optar pela profissão com que mais se identifica e a desenvolver uma atitude mais focada na sua carreira do que na empresa, muitas vezes priorizando seus próprios interesses e sua empregabilidade. Mesmo se submetendo aos valores das empresas, o jovem executivo de carreira parece ser regido de forma mais preponderante pela ética do prazer. Estes jovens saíram da adolescência tardiamente, o que Ihes possibilitou começarem a trabalhar ainda sem obrigações de sustento familiar.

A geração anterior, hoje sênior, teve o trabalho ocupando muito mais cedo um lugar central nas suas vidas, em uma época que o trabalho duro, árduo, era o que dava o significado e o lugar do indivíduo na sociedade, especialmente para os homens. Como único provedor da família, o indivíduo não cogitava desistir de um trabalho, mesmo que este não lhe proporcionasse prazer. A ética subjacente era a ética do dever.

Tanto executivos jovens de carreira quanto seniores, mesmo com ações e intensidades diferentes, se preocupam com a empregabilidade. $O$ executivo sênior faz parte de uma geração que, em sua maioria, trilhou o caminho profissional em uma única empresa. O mais jovem tenta focar a construção de sua carreira, independentemente da empresa na qual está no momento, e esse planejamento inclui a passagem por várias organizações (EVANS; BARTOLOMÉ, 1980).

O passar dos anos gera maior experiência de vida, que pode aumentar o equilíbrio e trazer uma atitude mais condescendente e mesmo mais positiva em relação às dificuldades no ambiente de trabalho (DEMO, 2005). Por outro lado, ser pai ou mãe pode aumentar a importância ou pressão sobre os mais jovens executivos de carreira para assumir de forma mais efetiva o papel familiar (MARTINS; EDDLESTON; VEIGA, 2002), o que tende a gerar tensão, pela falta de tempo para conciliar a vida profissional à pessoal justamente quando os filhos pequenos e o cônjuge demandam mais atenção.

\subsection{Jovens executivos herdeiros no cenário das organizações}

Herança e sucessão familiar são temas recorrentes na literatura (BELMONTE; FREITAS, 2013). As famílias transmitiam de pai para filho uma herança não só de sobrenome, mas também de profissão (BERNHOEFT, 1989). Na atualidade, esse quadro não mudou muito. A empresa 
familiar inicia sua vida a partir das aspirações e dos desejos de seu fundador. Parece coerente e natural aos filhos seguir os caminhos e os passos do progenitor e, quando é chegada a hora, o herdeiro sucessor é chamado e convocado a ocupar o lugar do pai (VIDIGAL, 2000).

Dados divulgados amplamente pelo SEBRAE ressaltam que, apesar de o número de empresas familiares ser muito grande, elas têm vida curta, uma expectativa média de apenas 24 anos, em comparação a uma vida média de 45 anos de empresas não familiares. Como se percebe, os caminhos trilhados pelo herdeiro nem sempre são fáceis e de sucesso.

A discussão da empresa familiar na literatura está centrada no processo sucessório. Os valores institucionais da empresa se identificam com o sobrenome da família e com a figura do fundador. Essa característica é preponderante entre as empresas familiares. Há, no entanto, um enorme caminho a ser trilhado no que concerne ao processo sucessório. Apresenta-se como o principal problema o despreparo geral, tanto do sucessor como do sucedido, em relação ao processo sucessório (LODI, 1998).

Na empresa familiar o interesse está bastante focado nas questões internas do negócio (família). Na empresa não familiar, o interesse está mais focado nos aspectos externos do negócio. $\mathrm{Na}$ empresa familiar estão presentes variáveis pessoais, afetivas, que the deram origem.

Assim, a solução do processo sucessório passa, necessariamente, pela estruturação de um bom plano de sucessão (BELMONTE; FREITAS, 2013). Para se alcançar tal objetivo, é necessário detectar quem está disposto a ser o sucessor, qual sua competência em gestão empresarial e até que ponto está preparado para assumir o comando da empresa. Destaca-se que é preciso conceder aos herdeiros liberdade e meios de seguirem seus próprios rumos profissionais, de maneira que não se sintam obrigados ou acomodados na empresa, por força de sua posição hereditária (BERNHOEFT, 1995).

Nessa mesma direção, Lodi (1998) afirma que a sucessão é um processo de transferência de poder que leva um longo tempo de maturação. O jovem executivo herdeiro deve ter consciência de que o sobrenome não é quesito suficiente para garantir que exercerá com qualidade suas atribuições para o jogo exigido para a liderança empresarial.

Baseado nesta discussão da literatura é que a pesquisa, cuja metodologia passa-se a descrever em seguida, se desenvolveu, com o fim de identificar, descrever e analisar a percepção de jovens executivos herdeiros sobre a satisfação com o equilíbrio no investimento de energia e tempo na vida profissional e na vida pessoal.

\section{PERCURSO METODOLÓGICO}

Para a realização da pesquisa, adotou-se a abordagem qualitativa, e a estratégia de pesquisa recaiu sobre a de caráter descritivo, operacionalizada a partir de um estudo de caso único (EISENHARDT, 1989; DEMO, 2000; YIN, 2001; 2005).

A população amostral caracterizou-se como não probabilística e intencional, por ter selecionado sujeitos por sua acessibilidade e tipicidade, e não com embasamento estatístico (VERGARA, 2004). A organização escolhida para este estudo foi o Programa FIEMG Jovem, organizado pela Federação das Indústrias do Estado de Minas Gerais - FIEMG, para desenvolvimento de novas lideranças. Limitado a 80 membros (eram 73 ativos no momento de início das entrevistas), são profissionais na faixa etária de 18 a 40 anos, ocupantes de cargos diretivos de empresas associadas ou filiadas aos sindicatos das indústrias. Nesse universo, verificou-se a predominância masculina (79,5\%).

Além disso, o disponível acesso aos membros do grupo foi relevante para a condução e conclusão da pesquisa, minimizando a criticidade que esse fator representa na obtenção de dados representativos para a estratégia e o método de pesquisa adotado (YIN, 2001, 2005). 
A amostra de entrevistados foi constituída por 15 jovens executivos herdeiros com idades entre 24 e 38 anos, sendo 12 homens e 3 mulheres, na faixa etária de 30 a 34 anos.

Essencialmente, as empresas onde os jovens executivos herdeiros dedicam seu tempo à carreira profissional foram fundadas há 25 anos ou mais pela geração dos pais ou dos avós dos entrevistados; e são de pequeno, médio e grande porte. Com a prosperidade dos negócios, ora sucedendo a atividade inicial, ora estimulando negócio complementar ou novo, o filho do dono atua na empresa como executivo no papel de comando geral do empreendimento ou área específica.

Como instrumento de pesquisa, utilizou-se entrevistas semi-estruturadas, tendo os dados sido organizados como forma de auxiliar na categorização e manutenção do propósito da pesquisa (TRIVIÑOS, 1987; SOY, 1997; GASKELL, 2002). As entrevistas aconteceram no local de trabalho dos entrevistados, nas empresas que estes jovens dirigem e que herdaram dos pais, em Belo Horizonte e Contagem.

$\mathrm{Na}$ análise de conteúdo a que se procedeu, procurou-se interpretar os dados de maneira que estivessem representados os aprendizados obtidos e as descobertas que confirmavam ou não as informações (GASKELL, 2002; CRESWELL, 2003). Os dados foram tabulados e recombinados para comparar com as perguntas iniciais e propósito do estudo, buscando as evidências para os seus achados como precaução e auxílio para evitar conclusões prematuras (YIN, 2005).

As categorias de investigação e análise que organizaram os dados a partir do roteiro de entrevista foram: 1. O impulso ao poder, buscando as referências de sucesso e a percepção de realização profissional dos jovens executivos herdeiros; 2 . o impulso ao trabalho, verificando as demandas da carreira, o teatro organizacional, as singularidades e as transformações no trabaIho dos jovens executivos herdeiros; 3 . Fontes de tensão dos jovens executivos herdeiros; e 4. A articulação das demandas da vida profissional e da vida pessoal dos jovens executivos herdeiros, conhecendo sua percepção de satisfação com o nível de equilíbrio alcançado.

\section{A ANÁLISE DOS DADOS}

A pesquisa de Tanure, Carvalho Neto e Andrade (2007), realizada com executivos de carreira, que não são herdeiros, foi utilizada na discussão da análise de dados como fator de comparação para reforçar as diferenças com os jovens executivos herdeiros, já que a percepção dos executivos de carreira é de muita dificuldade para equilibrar as demandas da vida profissional com as da vida pessoal. Veremos que os jovens herdeiros conseguem equilibrar bem melhor estas e outras demandas, embora haja alguns pontos de convergência, pois, afinal, todos pertencem ao universo da vida de executivos.

\subsection{Perfil dos jovens executivos herdeiros entrevistados}

Considerando que o fator idade já estava delimitado dentro do universo, o critério para a escolha dos jovens executivos herdeiros foi selecionar aqueles que já ocupavam posições no alto escalão das empresas com poder de decisão sobre as pessoas e as políticas da organização. Os cargos exercidos pelos participantes da amostra eram de 3 gerentes, 11 diretores e 1 presidente de empresa. Efetivamente, quase todos os entrevistados, além de diretores das empresas, eram donos do negócio.

As áreas de responsabilidade direta dos jovens executivos herdeiros estão distribuídas entre Comercial, Financeira, Geral e Administrativa. Todavia, esses profissionais interagem dentro de suas empresas e se ocupam de diversas atribuições. 
Vários dos entrevistados ocupavam funções e atividades em grupos técnicos ou de identidade político-social, como conselho de ética empresarial, de conselho de governança, diretoria de sindicato patronal e/ou associação nacional do setor empresarial. Alguns desses jovens executivos herdeiros narraram que participam ativamente em quatro ou mais grupos, com relato de um deles de exercer 13 posições em diversas entidades. Oito deles relataram participar, no momento, além do cargo na empresa, apenas do grupo FIEMG Jovem.

Em geral, os depoentes manifestaram que estiveram livres para a escolha da carreira profissional e para o curso de graduação superior. Também, relataram ter recebido incentivos (familiares) para uma formação que não fosse necessariamente aquela do pai. O curso de Administração se apresentou como o de maior frequência na primeira escolha de graduação dos entrevistados (9). Esse dado indica a possível influência do interesse em instrumentos objetivos ou técnicos que subsidiassem o futuro papel executivo. O Direito foi o curso de graduação de três dos executivos entrevistados.

Os relatos da presente pesquisa indicaram que a preocupação com os laços familiares e sociais é uma condição presente nos mais jovens e nos mais velhos entrevistados. Nos primeiros, os laços estão ligados aos pais, nos demais, à esposa e/ou filhos. E eles têm dedicado tempo e energia para desenvolver e manter essa dimensão da vida, evidenciando satisfação com o equilíbrio praticado na articulação das demandas entre vida profissional e pessoal. Da mesma forma, na amostra, essa percepção de satisfação esteve presente entre os entrevistados que declararam manter uma união estável (6) e aqueles em situação desimpedida (9), e entre a condição de terem filhos (5) ou não (10).

\subsection{O impulso ao poder: as referências de sucesso e a percepção de realização profissional}

Predomina, entre os jovens executivos herdeiros dessa amostra, a referência a um membro da família ou a um profissional de relacionamento muito próximo como imagem e reputação de sucesso: pessoas de valores e princípios éticos admiráveis, empresário, empreendedor, pai. Ser bem-sucedido para esse jovem executivo é a conquista de algo íntimo, individual. É manter a dedicação, a persistência, a vontade e a abnegação em cumprir uma missão em sua jornada de vida. Na maioria dos relatos, o sucesso de quem "saiu do nada" é central nos motivos da admiração que lhe deposita.

Para esses jovens, a carreira e a conquista de postos elevados na organização é um processo quase dado, não uma meta a que se dediquem prioritariamente. Comprometidos com suas responsabilidades e com a empresa, relataram que não estão dispostos a sacrificar sua vida pessoal pelo crescimento profissional.

Sem sentir pressão de falta de perspectiva ou do limitado espaço de crescimento na empresa, os entrevistados não sofrem como os executivos de carreira, que têm seu sentimento de pertencimento à empresa minado pela espera de oportunidades. $O$ fato de serem grandes, médias e até pequenas empresas que estes entrevistados já dirigem e onde virão assumir o cargo principal algum dia não deixa de ter influência nesta atitude mais tranquila de procurar preservar sua vida pessoal, já que o cenário está de certa forma dado, o papel esperado de ocupar o lugar do pai, pré-determinado.

Sem se mostrarem seduzidos pelo comando, que sabem que um dia será deles, ou já o é, por direito de herança, apontam para um diferente contrato: uma devoção hereditária. Condenados a vencer, são prisioneiros da obra do predecessor e o sentido está em dar continuidade na sua conquista. É o papel esperado desde muito jovens pelo pai, família e círculo social. 


\subsection{0 impulso ao trabalho: dedicado sim, workaholic não}

Comprometidos "até o sangue" com a empresa, os jovens executivos herdeiros entrevistados lidam com os desafios das 24 horas do dia e dos sete dias da semana de forma diferente dos executivos identificados nos dados apontados por outras pesquisas. Recorrente nos relatos, entrevistados "viram a noite trabalhando" e não trabalham durante os finais de semana, a menos que seja uma necessidade extraordinária. Ainda, os jovens executivos relataram não levar tarefas extraordinárias para casa e, majoritariamente, declararam que conseguem se desligar do trabalho quando estão com amigos ou familiares.

Afirmando trabalhar frequentemente em torno de dez horas por dia, sua dedicação afasta a condição da demasiada importância a essa dimensão e a abdicação de outros aspectos sociais em sua vida. Foram obtidas declarações que evidenciaram um amadurecimento deste jovem executivo herdeiros para lidar com as demandas do papel executivo. Entre elas, tem-se: "Eu tenho um limite, inclusive de horário de sair... eu me dedico muito, mas a minha vida não é em função do meu trabalho".

Em relação às férias, os relatos indicam que não há regularidade em tirar um período longo. Predomina, entre os entrevistados, usufruir finais de semana prolongados mais de uma vez durante o ano. É curioso notar que as férias clássicas de 30 dias começam a ficar distantes até do imaginário desses jovens. Neste aspecto, os relatos coincidem com o posicionamento dos executivos em geral da pesquisa de Tanure, Carvalho Neto e Andrade (2007).

Em momentos de dedicação a atividades de não-trabalho, como lazer ou compromissos familiares, manifestaram que conseguem se desligar, se distanciar da preocupação com o dia a dia dos assuntos relacionados ao trabalho. Foram registrados depoimentos tais como: "Consigo esperar o próximo dia"; e "Sei que os executivos, de forma geral, passam muito tempo dentro da empresa, e quando vão para casa não desligam. É isso que está acabando com os casamentos e com a saúde deles. Eu cuido de mim".

Quanto ao referencial de realização profissional, para os jovens executivos herdeiros dessa amostra, "um indivíduo sem ambição é um indivíduo sem futuro". Entretanto, foram unânimes em identificar ser necessário dosar o nível de ambição profissional, por reconhecê-la como uma força capaz de comprometer a qualidade das escolhas. Eles deixaram mostras de que lidam com a questão da ambição com certa tranquilidade, declarando que não estão dispostos a comprometer a disponibilidade para sua vida pessoal. Na percepção dos entrevistados, o tempo e a energia dedicados às demandas do trabalho "é o que é razoavelmente esperado para o cargo (que ocupa), dentro do que é preciso ganhar para atender às suas necessidades (econômicas) básicas". Possivelmente, o "berço", a herança da empresa, já lhes proporcionou um ponto de partida de expectativas e conquistas atendidas, que torna mais serena a sua forma de lidar com desejos e necessidades materiais.

Os relatos dos entrevistados apontam o exercício de ações efetivas de limite da invasão das demandas profissionais sobre o tempo e a energia dedicados à dimensão pessoal, posicionamentos que os distingue do fenômeno do workaholic.

Os jovens executivos herdeiros da presente pesquisa, majoritariamente, afirmaram não terem queixas quanto à carga de trabalho a que estão submetidos naquele momento. É verdade, entretanto, que o depoimento de diversos deles deixou evidências de que, em um passado recente, atravessaram situações críticas no âmbito da saúde pessoal em decorrência do excesso de trabalho.

Os relatos indicam que os jovens executivos herdeiros apresentam reconhecimento e compreensão sobre o elevado nível de incertezas e de influências gerais e diversas vezes incontroláveis que inibem o pleno êxito ou levam ao fracasso em projetos ou negócios. Embora seja motivo de insatisfação por afetar os resultados, os jovens executivos não sentem ânsia ou angústia com as limitações de controle dedicados a buscar resultados determinantes para o sucesso no negócio. 
Os jovens executivos herdeiros entrevistados assumiram ter como característica um espírito competitivo que os habilita a atuar e assumir o vínculo entre a força do cargo e as regras do jogo de mercado. Entretanto, é preciso ressalvar que está mais presente o sentimento de preservação e prosperidade do negócio que herdaram, e não o impulso competitivo presente nos executivos das grandes empresas diante da pirâmide de poder na qual querem subir, pois os espaços são limitados.

Os entrevistados relataram que se preocupam em serem percebidos pelo comprometimento e pela dedicação ao negócio. Para eles, sucesso está vinculado aos resultados apresentados, e não ao cumprimento de comportamentos rotulados, como o de um workaholic. Consideram-se satisfeitos com o aprendizado profissional e o desenvolvimento pessoal adquirido na esfera da organização.

Observa-se um paradoxo: a escolha do filho do dono seria um sim ao reconhecimento da necessidade de "suceder", com um não interditado à escolha da vocação pessoal para seguir em uma própria jornada. Esta tensão tem um peso considerável sobre esses jovens.

Além desses aspectos, de um lado convivem com o sentimento de querer fazer parte da empresa, sentem orgulho de ver o nome da família ligado a um negócio de sucesso. De outro, têm consciência que, se optarem por uma carreira profissional fora do negócio familiar, terão menos cobrança em relação ao seu desempenho, mas antecipam o sentimento de que poderão mais tarde ser cobrados justamente por não assumirem um papel que lhes estava destinado.

\subsection{O jovem executivo herdeiro: entre tensão e satisfação}

Os jovens executivos herdeiros buscam a formação acadêmica e a capacitação profissional sem as pressões de empregabilidade ou de mobilidade funcional. Esta característica difere dos grupos de executivos de carreiras das grandes empresas, conforme apresentado na literatura, que se apresentam quase como compulsivos na dedicação a cursos e mais cursos.

O curso de Administração apareceu como escolha mais frequente na formação entre os jovens executivos herdeiros desta pesquisa. A motivação destes para a escolha foi buscar uma preparação generalista em gestão e conhecer instrumentos que subsidiassem o exercício do papel de executivo.

Os dados revelam que, embora tivessem a possibilidade de percorrer a educação formal de nível superior e concluí-la antes de iniciar sua carreira profissional, estes jovens executivos herdeiros assumiram muito cedo tarefas diversas dentro das empresas. Em sua maioria, tiveram que assumir a posição de comando na empresa de forma antecipada, por algum fator não planejado pessoalmente ou mesmo pela organização, como, por exemplo, a perda da condição física do pai, do fundador.

No entanto, vários desses jovens executivos herdeiros ainda contam com a condição de ter o "alto comandante", o pai, quase que de forma vitalícia no cargo superior da organização. Essa estabilidade não é percebida pelo jovem executivo herdeiro como uma falta de oportunidade de crescimento pessoal, e ainda serve para preservar sua resistência emocional e sua saúde diante das mudanças profundas e constantes nas empresas.

Os dados coletados revelam que o jovem executivo que é herdeiro de uma grande empresa está satisfeito com sua capacidade de lidar e articular suas demandas profissionais. Eles declararam reconhecer seus limites pessoais diante da dificuldade de conseguir apresentar todos os resultados para as demandas cada vez maiores e mais complexas por parte das empresas, sem que isso se transformasse em insatisfação.

Além disto, os relatos dos entrevistados evidenciam uma diminuição da condição de primazia dada à dedicação de tempo e energia à dimensão trabalho. Nessa condição, a possibilidade de vivenciar mais intensamente as outras dimensões de sua vida pessoal contribui para aumentar a sensação de satisfação. 
Os jovens executivos herdeiros da presente amostra não se sentem ameaçados pelo quadro de mudanças. É uma reação que difere da percepção dos executivos da pesquisa de Tanure, Carvalho Neto, Andrade (2007), em que a vivência de mudanças radicais ou incrementais é um potencial de ampliação da sensação de dívida de que ele sempre tem que fazer mais, pois, do contrário, estará fora do "jogo".

Sua sobrevivência como profissional o coloca com a mesma sensação de estar condenado a vencer, porém não pelas mesmas razões dos executivos de carreira, que devem apresentar resultados de produtividade recorde a cada dia, potencializando, mais uma vez, a sensação de estar sempre devendo. Sua tensão é com o desafio de superar o êxito do seu predecessor e dar continuidade a seu trabalho como sucessor. Para esse ponto, os jovens executivos herdeiros desta amostra se apresentam muito mais como prisioneiro de uma herança.

Por diferentes maneiras, os entrevistados disseram se ocupar de atividades que se enquadram no modelo prescritivo formulados ainda no início do século passado, contidas em planejar, organizar, dirigir, coordenar e controlar. Também foram salientadas ações de facilitar a conciliação de posturas conflitantes, adaptar as pessoas ao processo de cooperação, tomar decisões e incutir o senso de valores na organização, estando atento, por exemplo, em não incentivar o workaholic ou que seus empregados vivam apenas a dimensão profissional, em detrimento da vida pessoal. Os relatos indicam que os jovens executivos herdeiros se ocupam de um trabalho marcado pela elevada variedade de tarefas, descontínuas e fragmentadas, e pelo envolvimento em múltiplos projetos.

Todavia, embora a declaração de gostar das tarefas de planejamento e de definição de estratégias esteja presente na maioria dos relatos, os registros quanto às demandas e exigências da carreira apontam para uma dedicação ostensiva às atividades diárias e operacionais, sem a reserva de algum tempo maior para estarem sozinhos e dedicados ao pensamento de temas estratégicos.

Por essas características da natureza do trabalho, confrontados com a possível sensação de dívida permanente, os jovens executivos herdeiros depuseram que compreendem ser uma condição inerente do mundo empresarial o elevado nível de demandas. O jovem executivo mineiro herdeiro também reconhece sua impotência para lidar com o volume de tarefas e com o ritmo de trabalho. Entretanto, ele não se coloca como refém ou aprisionado à alternativa de "ter que dar conta de tudo".

Por outro lado, na literatura discutida, a carga de trabalho, o nível de cobrança por resultados e metas foram avaliados como fatores de extrema insatisfação pelos jovens executivos de carreira. Os relatos destes jovens executivos herdeiros sugerem que estes fatores não são motivos para insatisfação na sua vida profissional.

Uma fonte de impacto na satisfação do executivo de carreira, como discutido na literatura, está relacionada com a sensação de "pertencimento" a uma empresa que se admira, de identificação de seus valores pessoais com os valores da organização. Essa sensação prazerosa de fazer parte de "algo maior", de "fazer a diferença", frases repetidas por muitos executivos de carreira na literatura discutida, esteve presente também nos relatos dos jovens executivos herdeiros.

Entretanto, a sensação de orgulho presente na vida do executivo de carreira das grandes empresas que chegou ao topo da direção sem ser através da herança tem maior significado para o indivíduo que se candidatou e venceu as fortes exigências impostas para tal conquista. Sendo o jovem executivo um "herdeiro", seu orgulho é gerado pelo sentido, identidade e significado do trabalho. Os relatos apontam para percepção de estarem fortemente influenciados de forma positiva pela sensação de possuir uma variedade de competências para lidar com as diversas tarefas, de que realizar algo percebido como significativo e de que o trabalho contribui para o bem-estar de outras pessoas. 
De forma geral, os jovens executivos herdeiros se mostraram preocupados com as contribuições do trabalho e da empresa para a sociedade. Consideram as implicações do trabalho para si mesmo, para os outros e para a sociedade. Apresentaram consciência de que o trabalho é um meio que transcende seus interesses particulares, e atuar como empresário deve ser enquadrado como dedicação a uma causa importante e significativa. A sua produção de riqueza gera para a sociedade empregos e dinamismo econômico.

Para a maior parte dos entrevistados, sua satisfação e orgulho se completam pelo exercício da autonomia, pois se sentem com liberdade e independência para realizar suas tarefas, com permissão para os ajustes necessários. Para poucos, permanece a sensação de que estão, ainda, sem condições de implementar suas estratégias e manobras empresariais de forma mais independente, devido à presença do pai ou de sentirem-se ainda com experiência insuficiente.

Sobre a confiança existente nas relações com as pessoas, a percepção do jovem executivo herdeiro desta amostra é que há um esforço das pessoas na sua empresa em auxiliá-lo na construção do conhecimento e no exercício do seu papel. Esse ponto diverge dos achados da literatura discutida neste trabalho, em que os executivos de carreira percebem haver um aproveitamento de suas fraquezas para prejudicá-los, num ambiente excessivamente exigente.

O executivo de carreira é prisioneiro do papel em que vivencia o fascínio que o cargo, o status, o poder e o dinheiro trazem para sua vida. Seu dilema é gerenciar o limite entre trabalho, lazer, vida afetiva e família (DE VRIES, 2004). Como exposto, o jovem executivo herdeiro da presente pesquisa não apresentou a tendência de confundir seu papel de executivo com sua identidade. Seus relatos dão conta de que ele sente o trabalho como uma parte da vida, mas não a mais divertida e prazerosa. A dedicação à vida pessoal, afetiva e familiar está presente como uma importante fonte de satisfação.

O depoimento da maioria dos entrevistados foi de que vivenciaram anteriormente o desequilíbrio pessoal no desempenhar do papel de executivo, que ocupou uma centralidade em sua dedicação. Entretanto, nesse momento posterior ao desequilíbrio inicial, disseram-se satisfeitos com a distribuição de energia e tempo dedicados às diversas dimensões da vida, evidenciando o uso de estratégias efetivas na articulação das demandas do trabalho e fora dele.

O excesso de "teatro" e "jogo de cena" não foi evidenciada na presente pesquisa. Se o chefe dita em boa medida o padrão do teatro corporativo, para o excesso ou para o equilíbrio, parece que o exemplo dado pelos jovens executivos herdeiros se aproxima da situação apontada como caso raro para os executivos de carreira por Tanure, Carvalho Neto e Andrade (2007). Ter hora de ir para casa está amplamente assumido pelos entrevistados e é no final do expediente normal, por volta das $18 \mathrm{~h} 30$.

Essa negligência na relação familiar não surgiu como prática dos jovens executivos herdeiros da presente pesquisa. Possivelmente, anteciparam-se na percepção da tristeza expressada pelos executivos sêniores de carreira por não terem acompanhado a vida dos filhos. Além disso, o fato do pai já ter-lhes garantido a posse da empresa, e de toda a relação empresa-família concentrar-se, facilita o convívio presencial familiar do jovem executivo herdeiro com seus pais.

Embora o papel na família seja visto como capaz de proporcionar menos oportunidades de realizar uma contribuição percebida como única pela sociedade, o jovem executivo mineiro, herdeiro, está atento para o impacto que a satisfação com essa dimensão tem sobre toda a sua condição de vida, e lhe dedica energia e tempo suficientes para manter o equilíbrio. 


\subsection{Articulando vida profissional e vida pessoal}

A sensação percebida pelo executivo de carreira de que o tempo é um recurso extremamente escasso para que ele se dedique à sua vida privada foi a primeira investigação da pesquisa. Assim, quanto ao uso do tempo, seria de se supor que fosse a primeira fonte de tensão ligada ao desequilíbrio na articulação entre as demandas da vida profissional e da vida pessoal. Afinal, a insatisfação do executivo com a falta de tempo para se dedicar à sua vida pessoal é apontada há quase trinta anos na literatura (EVANS; BARTOLOMÉ, 1980).

A pesquisa revelou que estes jovens executivos herdeiros dedicam dez horas em média ao trabalho; com um tempo médio de sono de sete horas, uma hora para uma refeição à noite $\mathrm{e}$ pelo menos meia hora para cuidados pessoais. Com necessidade de pelo menos uma hora para o deslocamento casa-trabalho-casa, sobram-Ihe quatro horas e meia para cuidar de sua dimensão pessoal: fazer uma atividade física, conviver com a família e amigos, além de ter um tempo para si, dedicando-se a momentos de puro lazer. Essa situação é melhor que o resultado da pesquisa de Tanure, Carvalho Neto e Andrade (2007), cuja análise apontou sobrar apenas duas horas e meia por dia "na melhor das hipóteses" para os executivos de carreira das grandes empresas se dedicarem à dimensão pessoal, contanto, ainda, com apenas seis horas de sono por noite.

Permanece a crença de que a qualidade do tempo dedicado aos diversos papéis é importante. Mas, também, ainda que seja variável de pessoa para pessoa e em relação ao estágio de vida em que se encontram, os jovens executivos herdeiros expressaram uma compreensão que a quantidade de tempo e de energia disponibilizadas para a vida pessoal são fundamentais para a percepção dessa qualidade acreditada como suficiente para sua satisfação integral.

Usuários contumazes de e-mail e celular, os jovens executivos herdeiros revelaram a capacidade de limitar e até impedir a "invasão" das demandas de sua energia e de seu tempo para a dedicação ao trabalho fora do horário de sua jornada habitual. Deixaram relatos da consciência dessa invasão do "aparelhinho do diabo" (Blackberry)" e de sua capacidade de avançar sobre os limites dos espaços pessoais, que passam a ser espaços também de trabalho.

Na presente pesquisa, foram obtidos relatos em dois extremos. De um lado, um grupo foi contundente em demonstrar saber utilizar os recursos tecnológicos, e muito contundente também sobre a capacidade de limitar a invasão desses recursos em seus momentos pessoais. Entretanto, durante as entrevistas, seus olhos não desgrudaram do "aparelhinho". Outros depoimentos revelaram a invasão da tecnologia na vida do jovem executivo herdeiro, como revela a declaração: "Sou psicótico, fico 24 horas on line" e "domingo, no final do dia, abro a minha caixa de e-mail para começar a segunda zerado". É uma condição que os enquadra como "escravos das novas tecnologias", condição preponderante de executivos identificados na literatura. Fator também considerado por Perrone, Engelman, Santos e Sobrosa (2013), quando dizem que os jovens interagem intensamente com a tecnologia.

Sobre o investimento de até metade do seu tempo e da energia na vida profissional, devido à carga de trabalho, a percepção dos jovens executivos herdeiros entrevistados é de satisfação com essa distribuição. Esse dado os coloca ao lado da minoria dos executivos de carreira da pesquisa de Tanure, Carvalho Neto e Andrade (2007), na qual só um quinto se apresentou como satisfeito com o equilíbrio alcançado.

Não surgiu, durante os depoimentos, a utilização do investimento de longo tempo e energia no trabalho como uma "fuga" dos aborrecimentos ou da incapacidade para lidar com os desafios das outras dimensões da vida. 
Esta pesquisa mostrou que a duração média das férias que os jovens executivos herdeiros tiram no ano é de 20 dias, divididos em dois ou três períodos. Essa média é superior aos achados de pesquisas discutidos na literatura, em que os dados indicaram ser de dez dias no ano. Reconhecendo que as exigências do cargo e o excesso de demandas empresariais são os fatores que dificultam o planejamento de férias mais longas, todos assumiram que têm se esforçado para lidar bem com o sentimento de "culpa" por tirar férias.

Indagados sobre as atividades com que se ocupam fora do trabalho os entrevistados salientaram o lazer físico, artístico, intelectual e, de forma predominante, o círculo social. A prática de exercícios físicos e de esportes é um complemento do cuidado com a saúde e com o bem-estar entre os jovens executivos herdeiros, sendo fonte de muita satisfação. Note-se que a maioria dos executivos de carreira citado na pesquisa de Tanure, Carvalho Neto e Andrade (2007) percebe a necessidade da prática de atividades físicas como um mal necessário.

Os jovens executivos herdeiros informaram nas entrevistas, que realizam regularmente viagens a trabalho e que elas têm, em média, duração de um dia. Predominam as viagens curtas, para visitas a clientes; outras, um pouco raras e mais longas, para participação em congressos e feiras setoriais com o fim de atualizar informações sobre o negócio ou prospectar oportunidades. A necessidade de dedicação de tempo para viagem é percebida como fator de insatisfação para todos os jovens executivos herdeiros, principalmente no momento de preparação, quando tem de lidar com a eminente ausência no ambiente de trabalho e da família. Entretanto, todos assumem que, ao estarem em viagem, lidam muito bem com a situação.

Os jovens executivos herdeiros relataram que o horário de almoço é utilizado para trabalho, seja com clientes externos ou dentro da empresa. Nesse caso, para fortalecer "a rede de contatos e de informação", conforme expressado por mais de um deles.

Todos os entrevistados disseram gostar muito do trabalho de um modo geral, ainda que não de todas as atividades. Ainda que todos falassem sobre sua autonomia no trabalho, foi possível observar insatisfação com as políticas de recursos humanos e as práticas em suas próprias organizações. Demonstraram sensibilidade com as condições sociais dos empregados, mas apresentaram dificuldades para lidar com a falta de percepção do empregado quanto ao esforço da empresa ou deles próprios (jovens executivos herdeiros) em oferecer as condições possíveis para o trabalhador. Nestes casos, reputam ao empregado uma incompreensão quanto aos limites econômicos ou financeiros da empresa para prestar-lhe uma melhor assistência, seja salarial, seja em outros benefícios.

Todos afirmaram fazer um controle do trabalho dos funcionários por resultados, mesmo relatando dificuldades em delegar atividades e cumprir o papel de verificar ou cobrar por resultados planejados. Como eles definem a própria atividade: "fazer acontecer"; "sou um motivador"; "fazer contatos e parcerias"; "tocar o dia-a-dia e ver a coerência com a estratégia da empresa"; "manter contatos e antecipar projetos".

Em relação à distribuição do tempo entre a vida profissional e a vida privada ou pessoal, aqui entendida como as dimensões do não-trabalho, os relatos dos jovens executivos herdeiros indicam que eles dedicam metade de seu tempo à vida profissional, sendo a outra parte destinada a atividades fora do trabalho, para sua família, amigos e lazer.

De modo geral, os resultados da presente pesquisa explicitam uma melhor distribuição do tempo pelos jovens executivos herdeiros, sendo o tempo de não-trabalho trazido ao mesmo plano do tempo de trabalho, tendo como conseqüências um elevado nível de satisfação pessoal com o equilíbrio entre as dimensões de sua vida e do trabalho. Por outro lado, o peso das expectativas dos pais sobre estes herdeiros é fator de tensão e apreensão. 


\section{CONSIDERAÇÕES FINAIS}

Este estudo revelou fontes de satisfação e de insatisfação, e também fontes de pressão relacionadas ao conteúdo e ao contexto do trabalho desses jovens executivos herdeiros. Ficou evidente o cuidado que esses jovens executivos herdeiros apresentam para manter sua satisfação com investimento de tempo e energia nas diversas dimensões de sua vida. Isso é significativo, posto que os estudos abordados no referencial teórico mostram o contrário em relação aos executivos de carreira de grandes empresas que não são herdeiros. Os jovens executivos herdeiros não sofrem as mesmas tensões dos executivos de carreira, mas apontam uma insatisfação, não porque não conseguem equilibrar vida pessoal e vida profissional, mas porque, aparentemente, não escolheram ser executivo. Não tiveram que descobrir sua vocação.

Mantido o olhar sobre o jovem executivo herdeiro, as narrativas dos entrevistados expressam uma certa angústia do "filho do dono" diante das situações de submissão ao pai (expectativa familiar), confrontadas com os atrativos conscientes e inconscientes da sua opção pela empresa, pelo papel esperado pelo pai, pela família do jovem executivo herdeiro.

Sendo a sucessão configurada como um jogo em que as performances se sucedem, em que cada um se prepara para seguir sozinho, mesmo diante de negociações que aproximam e afastam pai e filho, a empresa se constitui no objeto de disputas, sujeita a perdas significativas.

Vários foram os relatos dos jovens executivos herdeiros sobre sua entrada na empresa em funções básicas, com passagem por diversos ou todos os setores. $O$ entendimento desses profissionais é que essa seria a melhor maneira de desenvolver uma ampla competência (conhecimento, habilidades e atitudes) para a promissora e inalienável carreira de "dono do negócio". Seria, pois, uma ótima entrada pela porta dos fundos para, em "humilde" posição, assumir o topo com a credencial elevada por ter percorrido a via crucis do merecimento.

Como visto na literatura discutida, os executivos de carreira lutam pelo cargo de poder que não ganharam dos pais com todas as armas que tem, trabalhando excessivamente para isto. Sofrem com a dificuldade de se manterem no topo, mas não abrem mão da posição e dos ganhos que este poder lhes proporciona. Já os jovens executivos herdeiros não tiveram que lutar pelo cargo de poder que ocupam.

O jovem executivo herdeiro, com o não interditado, apresenta, talvez, uma menor possibilidade de sentir prazer na dimensão trabalho. É nessa situação que a necessidade de sentir prazer será maior; e portanto, buscada em outra dimensão de sua vida.

Para o jovem executivo herdeiro, vê-se como possível a trajetória atravessada por uma metáfora que poderíamos relacionar com a fábula de Pinóquio. Criado para atender ao desejo do "artesão", Pinóquio, assim como o executivo herdeiro, é criado para atender ao desejo do pai. É sua natureza no mundo. Sua peleja será para instalar-se na realidade, diante do artesão, pai, diante da sociedade, como sujeito de suas escolhas. Não faltam nessa história personagens para instruir, atrair, insuflar ou desafiar o personagem que se constrói ao longo de sua jornada.

Para os executivos de carreira, "desequilibrados" na articulação do tempo para se dedicar às demandas das diversas dimensões da vida, serve outra metáfora, a de "Alice no país das maravilhas". Diante do dilema do tempo como principal fator de insatisfação desse profissional, serve o apressado Coelho Branco com seu tempo no relógio constantemente atrasado para alguma (qualquer) coisa. Como dito, o executivo de carreira se reveste do papel de excelência e exemplo. Serão os demais profissionais das empresas (não executivos), então, ingênuas "Alices" a seguirem esse "apressado coelho" que entra pelo buraco?

Diversos são os limites inerentes ao estudo realizado. Além da impossibilidade de verticalização intrínseca dos resultados nos estudos qualitativos, tem-se a interdisciplinaridade dos 
questionamentos como a Psicologia, a Antropologia e a Sociologia. É um exercício que exige apreciações multifacetadas do indivíduo e de seu percurso formativo, individual e de escala de comando nas organizações. Há que se considerar o caráter subjetivo na percepção sobre a questão do sucesso, da satisfação do jovem executivo herdeiro e de suas estratégias desenvolvidas para articulação entre vida profissional e pessoal. Mesmo sendo a idade um dado objetivo, e os resultados encontrados indicarem haver fatores característicos entre os grupos etários, o dado mais significativo dá-se pelo fato de ser filho do dono, pois pode-se observar através da pesquisa que ser herdeiro é uma condição de grande impacto sobre todos os fatores determinantes do sentimento e da ação deste profissional.

Como protagonistas na dinâmica organizacional, vivenciando conflitos e contradições, na sobrecarga ou não e na compressão pelos espaços do poder, os jovens executivos herdeiros contam agora com uma nova demanda: ter sucesso e ser feliz. Os resultados dão indicativos de um ampliado lado sol para esse contingente de profissionais mineiros, por seu comportamento de preservação da possibilidade de investir verdadeiramente nas diversas dimensões da vida, como as relações afetivas, familiares e de lazer.

Segundo a literatura, o executivo de carreira desenvolve uma atitude mais focada em sua carreira do que na empresa, muitas vezes priorizando seus próprios interesses, pesando bem mais o custo e o benefício. Os entrevistados, jovens executivos herdeiros, diante dessa condição, respondem com um comprometimento duplo: à empresa, como patrimônio e origem subjacente do sentimento de dever, e à dimensão pessoal, como fonte de prazer. As evidências dão conta que empunham mais claramente a bandeira do bem-estar pessoal, revelam que o jovem executivo herdeiro, "filho do dono", não está disposto a sacrificar sua vida pessoal pelo progresso na carreira. Não a idade, mas a condição da herança, como já mencionado, parece fundamental para a situação de satisfação e de equilíbrio na dedicação de tempo e energia à dimensão pessoal da vida dos entrevistados.

Cabe, como reflexão final, relatar a percebida importância de não se negligenciar a discussão do assunto sucesso-felicidade entre sucessores e predecessores (sucedido) nos estudos desse fenômeno de dimensão universal, a sucessão em empresa familiar. Possivelmente, é uma situação que abriga repercussão conflitiva, capaz de deixar vulnerabilidades nas pessoas físicas e jurídicas envolvidas.

Considerando, por um lado, a tendência do jovem executivo herdeiro, ao equilíbrio na dedicação de tempo e energia entre a vida profissional e pessoal e, por outro, a insatisfação com o peso da escolha pela carreira executiva no negócio legado pelo pai, faz-se necessária uma análise mais criteriosa dos fatores que contribuem para essa obediência. A expectativa é que o presente estudo colabore para o debate do tema instigando novas pesquisas: diante da ambivalência de sentimentos que predomina nas relações de poder deslocadas do ambiente familiar para o foro empresarial, estaria a sobrevivência da empresa também ligada à vocação do sucessor? Estaria a vulnerabilidade da empresa sob a condição do herdeiro em fazer (ou não) a escolha? Esta é uma temática para futuros estudos, suscitada por este trabalho. 


\section{REFERÊNCIAS}

AUBERT, Nicole. A neurose profissional. In: CHANLAT, Jean-François. (Coord.) $\mathbf{O}$ indivíduo na organização: dimensões esquecidas. São Paulo: Atlas, 2007.

ANTUNES, Ricardo. Adeus ao trabalho?: ensaio sobre as metamorfoses e a centralidade do mundo do trabalho. São Paulo: Cortez; Campinas: Ed. da UNICAMP, 1995.

BELMONTE, Victor Antonio Barros; FREITAS, Wesley Ricardo de Souza. Empresas familiares e a profissionalização da gestão: estudo de caso em empresas paulistas. Revista de Administração da UFSM. Brazilian Journal of Management, Rio Grande do Sul, v.6, n.1, jan/ mar. 2013.

BERNHOEFT, Renato. Empresa familiar: sucessão profissionalizada ou sobrevivência comprometida. São Paulo: Nobel, 1989.

BERNHOEFT, Renato. Manual de sobrevivência para sócios herdeiros. São Paulo: Nobel, 1995.

BULGACOV, Y; TOLEDO, S. Cultura organizacional e identidade: implicações dos ritos de passagem na identidade de jovens executivos trainees em uma organização multinacional. Curitiba: XXVIII EnANPAD, 2004, Anais...

CASTELLS, Manuel. A sociedade em rede - a era da informação: economia, sociedade e cultura. 9. ed. São Paulo: Paz e Terra, 1999. v. 1.

CHANLAT, Jean-François. Quais carreiras e para qual sociedade? Revista da Administração de Empresas, São Paulo, v. 35, n. 6, p. 67-75, nov./ dez. 1995.

CHANLAT, Jean-François. Ciências sociais e management: reconciliando o econômico e o social. São Paulo: Atlas, 2000.

DAVEL, Eduardo; MELO, Marlene C. O. L. Gerência em ação: singularidades e dilemas do trabalho gerencial. Rio de Janeiro: FGV, 2005.

DE VRIES, M. K. Putting Leaders on the Couch. Harvard Business Review, Jan. 2004, p. 65-71.

DEJOURS, Christophe. Uma nova visão do sofrimento humano nas organizações. In: CHANLAT, J.-F. (Dir.) O indivíduo na organização dimensões esquecidas. São Paulo: Atlas, 1996. v. 1.

DEMO, P. Auto-ajuda: uma sociologia da ingenuidade como condição humana. RJ: Vozes, 2005.

DEMO, P. Metodologia do conhecimento científico. São Paulo: Atlas, 2000.

DUMAZEDIER, J. Sociologia Empírica do Lazer. São Paulo: Perspectiva, 1979.

EISENHARDT, Kathleen M. Building thories from case study research. Academy of Management Review, v. 14, n. 4, p. 532-550, 1989.

ENRIQUEZ, Eugène. Da horda ao Estado: psicanálise do vínculo social. RJ: Jorge Zahar, 1990.

ENRIQUEZ, Eugène. O homem do século XXI: sujeito autônomo ou indivíduo descartável. RAE-eletrônica, v. 5, n. 1, art. 10, jan./jun. 2006.

EVANS, Paul. Carreira, sucesso e qualidade de vida. Revista de Administração de Empresas, São Paulo, v. 36, n. 3, p. 14-22, jul./ago./set. 1996.

EVANS, Paul; BARTOLOMÉ, F. Must success cost so much? London: Grant McIntyre, 1980.

FREITAS, Ernani Cesar; BARTH, Mauricio. De pai para filho: a complexidade e os desafios da gestão das empresas familiares. Revista de Administração da UFSM. Brazilian Journal of Management, Rio Grande do Sul, v.5, n.3, set/ dez. 2012.

GASKELL, George. Entrevistas individuais e grupais. In: BAUER, Martin W.; Pesquisa 
Qualitativa com texto, imagem e Som: um manual prático. Petrópolis: Vozes, 2002. p. 64-89.

GILL, Rosalind. Análise de discurso. In: BAUER, Martin W.; GASKELL, George. Pesquisa qualitativa com texto, imagem e som: um manual prático. Petrópolis: Vozes, 2002, p. 244-270.

HUY, Q. N.; MINTZBERG, $H$. The rhythm of change. MIT Sloan Management Review, $p$. 79-84, Summer, 2003.

KILIMNIK, Zélia; SANT'ANNA, Anderson; CASTILHO, I. Anderson; Competências e modernidade organizacional: profissionais mais competentes, políticas e práticas de gestão mais avançadas? República Dominicana: CLADEA, 2004, anais...

LAPIERRE, L. Imaginário e liderança. São Paulo: Atlas, 1995.

LODI, João Bosco. A empresa familiar. São Paulo: Pioneira, 1998.

MARTINS, L. L.; EDDLESTON, K. A.; VEIGA, J. F. Moderators of the relationship between work-family conflict and career satisfaction. Academy of Management Journal, v. 45, n. 2, p. 399-409, 2002.

MINTZBERG, Henry. Trabalho do executivo: o folclore e o fato. São Paulo: Nova Cultural, 1986. n. 3, p. 5-37. (Coleção Harvard de Administração)

MORIN, Estelle M. Os sentidos do trabalho. Revista de Administração de Empresas, São Paulo, v. 41, n. 3, p. 8-19, jul./set. 2001.

OSTROFF, C.; ATWATER, L. E. Does whom you work matter? Effects of referent group gender and age composition on managers' compensation. Journal of Applied Psychology, v. 99, n. 4, p. 725-740, 2003.

PAGÈS, Max et al. O poder das organizações. 1. ed. 10. reimpr. São Paulo: Atlas, 2006.
PERISTA, H.; MAXIMIANO, S.; FREITAS, F. Família, gênero e trajetórias de vida: uma questão de (usos do) tempo. In: CONGRESSO PORTUGUÊS DE SOCIOLOGIA, 4., Coimbra, 2000. Anais eletrônicos... Disponível em: <http://www.aps.pt/ivcong-actas/Acta166. PDF>. Acesso em: 15 dez. 2012.

PERRONE, Cláudia Maria; ENGELMAN, Selda; SANTOS, Anelise Schaurich; SOBROSA, Gênesis Marimar Rodrigues. A percepção das organizações pela geração Y. Revista de Administração da UFSM. Brazilian Journal of Management, Rio Grande do Sul, v.6, n.3, jul/ set. 2013.

PIMENTA, Roberto C.; THIRY-CHERQUES, Hermano R. Interpretação da referência moral dos jovens executivos nas organizações brasileiras. Salvador, XXX EnANPAD, 2006, anais...

RUIZ, Castor B. Os paradoxos do imaginário. Rio Grande do Sul: Unisinos, 2003.

SCANFONE, Leila; CARVALHO NETO, Antônio M. de; TANURE, Betânia. Tempos de trabalho e de não-trabalho: o difícil equilíbrio do alto executivo entre a carreira, as relações afetivas e o lazer. Rio de Janeiro, XXXI EnANPAD, 2007, anais...

SCHIRATO, Maria Aparecida R. O percurso do jovem executivo na arquitetura do poder das organizações sob o ponto de vista psicanalítico. Tese (Doutorado em Educação) Faculdade de Educação, Universidade de São Paulo, São Paulo, 2006.

SENNETT, Richard. Autoridade. Trad. Vera Ribeiro. Rio de Janeiro: Record, 2001.

SENNETT, Richard. A corrosão do caráter: consequências pessoais do trabalho no novo capitalismo. 4. ed. Rio de Janeiro: Record, 2000.

SERVA, M.; FERREIRA, J. L. O. O fenômeno workaholic na gestão de empresas. In: Curitiba, XXVIII EnANPAD, 2004,. Anais... 
SOLOMAN, C. M. Como lidar com a nova geração de administradores - os baby busters. Revista Administração de Empresas, São Paulo, v. 34, n. 2, p. 78-87, 1994.

SOY, Susan K. The case study as a research method. University of Texas. 1997. Disponível em: $\quad$ http://www.gslis.utexas.edu?essay/ users/1391d1b.htm> . Acesso em: 11 nov. 2012.

TANURE, Betânia; CARVALHO NETO, Antônio M. de; ANDRADE, Juliana. Executivos: sucesso e (in)felicidade. Rio de Janeiro: Elsevier, 2007.

TANURE, Betânia; EVANS, Paul; PUCIK, Vladimir. Gestão de pessoas no Brasil: virtudes e pecados capitais. Rio de Janeiro: Elsevier, 2006.

TERSAC, G; TREMBLAY, D.G. Quelques tensions contradictoires de l'evolution du temps de travail. Où va le temps de travail ? Paris : Octareès, 2000.

TOLEDO, Samantha. Carreira e identidade: reflexos das exigências mercadológicas na vida pessoal e profissional dos jovens executivos. Salvador, XXX EnANPAD, 2006, anais...

TREMBLAY, D.-G. Work-family balancing and working times: results from a research conducted in Canada. In: INTERNATIONAL INDUSTRIAL RELATIONS CONGRESS, 2002, Tokyo. Selected Papers from... Tokyo, Japan Institute of Labor, p. 223-237.

TREMBLAY, D.-G. Desafios da conciliação entre trabalho e família nas empresas canadenses: experiência sindical e gestão de recursos humanos. Curitiba, XXVIII EnANPAD, 2004, anais...

TRIVIÑOS, A. W. S. Introdução à pesquisa em ciências sociais: a pesquisa qualitativa em educação. São Paulo: Atlas, 1987.

VERGARA, S. C. Projetos e relatórios de pesquisa em administração. São Paulo: Atlas, 2004.
VIDIGAL, Antônio Carlos. A sobrevivência da empresa familiar no Brasil. RAUSP, v.35, n.2, abril/junho, 2000.

YIN, Robert K. Estudo de Caso: Planejamento e métodos. 3. ed. Porto Alegre: Bookman, 2005. 